\title{
Longitudinal studying of cognitive deficits in children and adolescents with schizophrenia spectrum disorders
}

\section{Anton Khromov ${ }^{1,2}$, Natalia Zvereva 2,1}

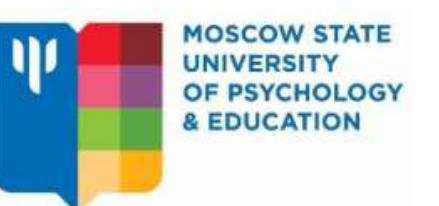

${ }^{1}$ Moscow State University of Psychology \& Education (MSUPE), Department of Neuro- \& Pathopsychology of Development, Moscow, Russia.

2Mental Health Research Center, Department of clinical

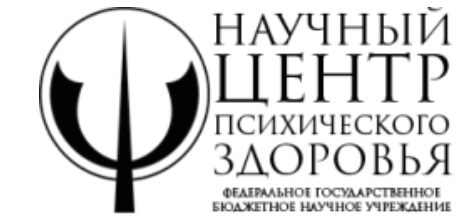
psychology, Moscow, Russia.

Background: There are clear evidences of cognitive impairment in adult patients associated with schizophrenia onset and observed later in their lives. Studies of dynamics of cognitive deficits in children and adolescents with early onset schizophrenia are rare. The aim of present study is to longitudinally assess dynamics of cognitive deficit in children and adolescents

Methods: Cognitive deficits of 24 patients (14 males, mean age $12.1 \pm 1.9$ years on baseline) with schizophrenia spectrum disorders (F20.8 - childhood onset schizophrenia, F21 - schizotypal disorder, and F2x x - undifferentiated schizophrenia) were assessed twice with average interval 1.5 years (from 0.3 to 3.7 years). Group of 32 children and adolescents without psychiatric diagnoses (18 females, mean age $12.5 \pm 2.7$ years on baseline) was used as healthy control and were assessed twice with interval of 1.0 year (Table 1 ).

Pathopsychological methods were used to assess cognitive functions (memorizing, attention and conventionality of thinking) then transformed to parameters of cognitive deficits (with z-transformation comparing the healthy peer's values). Parameters of cognitive deficits (z-values) were combined into several types of cognitive development (Zvereva, Khromov, 2014): severe deficit ( $\mathrm{z}<$ $-2.0)$, mild deficit $(-2.0<z<-1.5)$, normal $(-$ $1.5<z<1.5$ ), distorted (combination of -1.5 $<z$ and $z>1.5)$ and surpassed $(z>1.5)$.
Table 1. Samples characteristics

\begin{tabular}{|c|c|c|c|c|c|c|}
\hline \multirow[b]{2}{*}{ Groups } & \multirow{2}{*}{$\frac{\frac{\mathrm{o}}{\mathrm{N}}}{\sum}$} & \multirow{2}{*}{ 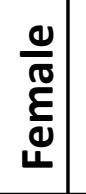 } & \multirow{2}{*}{ 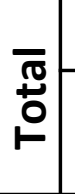 } & \multicolumn{2}{|c|}{ Age, years } & \multirow{2}{*}{$\begin{array}{c}\text { Mean } \\
\text { interval, } \\
\text { years }\end{array}$} \\
\hline & & & & Base & Follow-up & \\
\hline ealthy & 18 & 14 & 32 & $12.5 \pm 2.7$ & $13.5 \pm 2.7$ & $1.0 \pm 0.0$ \\
\hline atients & 10 & 14 & 24 & $12.1 \pm 1.9$ & $13.6 \pm 1.7$ & $1.5 \pm 0.7$ \\
\hline \multicolumn{7}{|c|}{ oatients by diagnoses: } \\
\hline F20.8 & 2 & 3 & 5 & $11.8 \pm 2.6$ & $12.7 \pm 2.4$ & $0.9 \pm 0.3$ \\
\hline$F 21$ & 4 & 7 & 11 & $11.9 \pm 1.7$ & $13.6 \pm 1.5$ & $1.7 \pm 0.8$ \\
\hline$F 2 x\rangle$. & 4 & 1 & 8 & 1.7 & $14.1 \pm 1.5$ & $1.5 \pm 0$ \\
\hline
\end{tabular}

\section{Findings}

Patients maintained firm signs of cognitive deficits during follow-up period (Fig.1). Level of healthy peers' cognitive functions were stable either. Patients with diagnoses childhood onset schizophrenia (F20.8) and schizotypal disorder (F21) maintain deficit of conventionality of thinking, whereas the level of attention deteriorates in patients with undifferentiated schizophrenia (F2x.x). Within group comparison revealed no significant differences in the deficit level expect for improvement of attention level in patients with schizotypal disorder $(Z=2.578, p=$ 0.010).

Assessment of types of cognitive development revealed that half of patients maintain severe and mild deficits types (Fig.2). Majority of the patients with severe deficit (5 of 9 ) at baseline kept severe deficit in follow-up, only two of them improved their parameters to normal level.

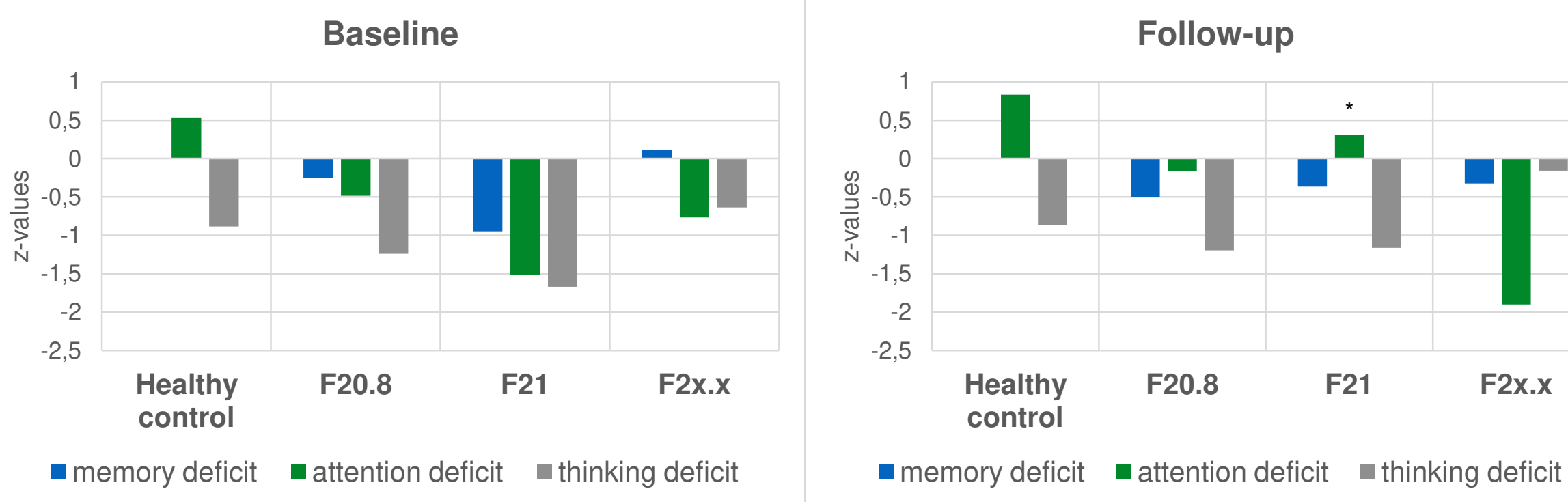

g. 1. Mean z-values of cognitive processes on baseline and follow-up in healthy control and in patients (by diagnosis). ${ }^{*} p<0.05$

Patients with mild deficit at baseline demonstrated multidirectional dynamics: some patients improved to normal or surpassed, others remained their level of deficit. From 10 patients with normal cognitive development at baseline 3 patients remained that cognitive type $(33 \%), 4$ patients impaired into mild or severe deficit $(40 \%)$ and 3 patients improved to normal or surpassed type (33\%). In overall $38 \%$ of patients retained severe deficit.

There is relation of deficit with clinical factors in patients. In particular the level of deficit of conventionality of thinking increased with duration of illness, especially in patients with 10 years of illness or more.

Discussion and conclusion

Despite the complexity of interaction between continuing cognitive development and psychopathology process in children and adolescents with schizophrenia disorders one might expect cognitive impairing in the course of time. Our findings suggest two possible interpretations: 1) patients with severe cognitive impairment retain stable deficiency over time; 2) patients with mild or partial cognitive deficit have better prognosis but the trajectory of their development needs more detailed investigation taking into account such factors as sex, age of illness onset, diagnosis progression, psychopathological syndrome etc.

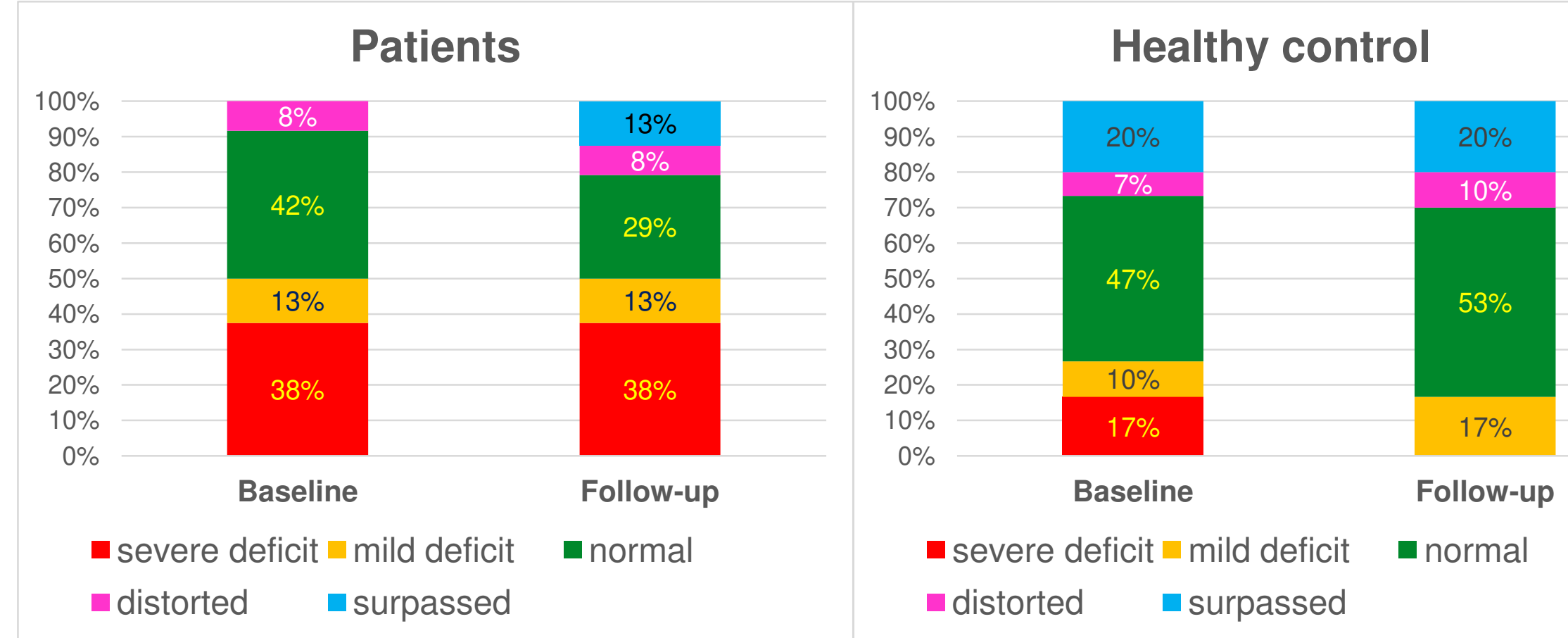

Fig. 2. Distribution of types of cognitive development in healthy control and in patients (all diagnoses).

References

Zvereva N.V., Khromov A.I. (2014) Particularity of Cognitive Deficits in Children and Adolescents with Schizophrenia: Clinica and Age-Related Factors. Medicinskaya psihologiya v Rossii, Vol. 6, No. 1, p. 7. - doi:10.24411/2219-8245-2014-00005 [in Russian, in English]

Authors have no conflicts of interest e-mail: hromovai@mappu.ru Copyright $\odot 2019$ Khromov A. Zvereva N 